\title{
O RELATIVISMO CULTURAL COMO INSTRUMENTO DE EXERCÍCIO DA CIDADANIA DAS PESSOAS COM DEFICIÊNCIA INTELECTUAL NO BRASIL À LUZ DA CONVENÇÃO SOBRE OS DIREITOS DAS PESSOAS COM DEFICIÊNCIA DA ONU
}

\section{THE CULTURAL RELATIVISM AS AN INTRUMENT FOR THE EXERCISE OF CITIZENSHIP BY PEOPLE WITH INTELLECTUAL DISABILITY IN BRAZIL ACCORDING TO THE UN CONVENTION OF THE RIGHTS OF PERSONS WITH DISABILITIES}

\author{
${ }^{1}$ Antônio Albuquerque Toscano Filho \\ ${ }^{2}$ Ana Luísa Celino Coutinho
}

\section{RESUMO}

O presente estudo, de natureza aplicada, método qualitativo e enfoque dedutivo e sistemático, se vale de levantamento bibliográfico e documental a fim de discutir o direito fundamental do exercício da cidadania da pessoa com deficiência intelectual, tendo como instrumento de sua efetivação o Relativismo Cultural. Busca-se evidenciar a visão abstrata e formal da universalidade dos direitos humanos, o desrespeito do Estado brasileiro e demais motivos determinantes para a inefetividade da Convenção sobre os Direitos das Pessoas com Deficiência, com vistas ao combate à discriminação e promover à efetivação do exercício da cidadania das pessoas com deficiência intelectual.

Palavras-Chave: Relativismo Cultural; Universalismo; Direitos Humanos; Deficiência Intelectual; Cidadania.

\begin{abstract}
This applied work study, assessed by a qualitative method and deductive approach, uses a documental and bibliographical survey to discuss the fundamental right of the exercise of the citizenship by people with intellectual disability, having the Cultural Relativism as its instrument of strengthening. It aims to display the formal and abstract vision of the universality of the Human Rights, the disrespect by the Brazilian State and other determining reasons for the Convention of the Rights of Persons with Disabilities ineffectiveness, in order to fight discrimination and to promote the achievement of the exercise of citizenship by people with intellectual disability.
\end{abstract}

Key Words: Cultural Relativism; Universalism; Human Rights; Intellectual Disability; Citizenship.

\footnotetext{
${ }^{1}$ Mestrando em Ciências Jurídicas pela Universidade Federal da Paraíba - UFPB, Paraíba (Brasil). E-mail: antoniotoscano.adv@gmail.com

${ }^{2}$ Doutora em Direito Público pela Universidade Federal de Pernambuco - UFPE, Pernambuco (Brasil). Professora permanente do programa de Pós-Graduação em Ciências Jurídicas pela Universidade Federal da Paraíba - UFPB, Paraíba (Brasil). E-mail: aluisacc@gmail.com
} 


\section{INTRODUÇÃO}

A história da humanidade aduz diversos episódios em que o indivíduo pertencente a um determinado grupo social era tratado de forma discriminatória e, em certos casos, de maneira cruel ou degradante pelo simples fato de possuir alguma característica diferente do padrão cultural estabelecido ou mesmo diante de interesses governamentais. Contudo, a evolução histórica aponta para o reconhecimento da posição proeminente que a pessoa humana ocupa no mundo, levando à construção da ideia de que nenhum indivíduo pode afirma-se superior aos demais, independentemente de suas características.

A partir da Convenção sobre os Direitos das Pessoas com Deficiência da ONU e de seu Protocolo Facultativo, ambos de 2006, vem se buscando dotar os Direitos Humanos básicos desse grupo social de múltiplas garantias, que lhes possam assegurar uma cidadania plena, como o direito à educação, à participação na vida pública e política, o acesso à justiça, e aquelas concernentes as relações familiares como o casamento, a constituir família, à maternidade e paternidade e à vida sexual.

Na percepção sociojurídica atual, a Convenção - incorporada à legislação brasileira em $2008^{3}$, inaugurou gramática de afirmação de direitos historicamente conspurcados, à vista dos processos de exclusão e desempoderamento que marcam essa categoria de sujeitos sociais, ainda que o novo panorama não tenha resultado em medidas efetivas para que o Estado brasileiro venha a eliminar a discriminação contra pessoas com deficiência intelectual em diversos âmbitos dos direitos fundamentais destes sujeitos.

Dito de outra forma, levando-se em consideração dados colhidos no Relatório brasileiro sobre o cumprimento das disposições da Convenção (2008-2010) ${ }^{4}$ e outros documentos congêneres, o Estado brasileiro não conseguiu garantir a compatibilização entre a produção normativa doméstica e a Convenção da ONU, acabando por mitigar a efetividade e aplicabilidade imediata que se deveria garantir a esse complexo normativo. Ou seja, o discurso de afirmação/efetivação dos direitos humanos encartado na referida convenção, com

\footnotetext{
3 Aprovado pelo Congresso Nacional por meio do Decreto Legislativo $\mathrm{n}^{\mathrm{o}} 186$ (ato normativo com força constitucional, à luz do art. $5^{\circ}, \S 3^{\circ}$ ), posteriormente promulgado pelo Decreto presidencial n ${ }^{\circ} 6.949$, de 2009.

${ }^{4}$ Ao ratificar a Convenção sobre os Direitos das Pessoas com Deficiência, o Brasil e demais Estados Partes comprometem-se a apresentar ao Secretário-Geral das Nações Unidas, de acordo com o $\S 1^{\circ}$ do art. 35, relatório de monitoramento sobre a medidas tomadas para cumprir as suas obrigações com a Convenção, no prazo de dois anos após a entrada em vigor da Convenção no Brasil e, posteriormente, pelo menos a cada quatro anos, e sempre que for solicitado pelo Comitê dos Direitos das Pessoas com Deficiência da ONU, conforme o parágrafo $\S 1^{\circ}$ do art. 36 .
} 
toda a força lógico-legitimante a ele vinculado, esbarra na concepção universalista dos direitos humanos, pois a concepção da dignidade da pessoa com deficiência intelectual é encarada de formas diferentes em determinadas culturas.

Diante da diversidade cultural experimentada no mundo, e em especial no Brasil, os direitos humanos apresentam-se como ferramentas capazes de influenciar o comportamento das comunidades, todavia, em face do multiculturalismo existente, esses mesmos direitos são tratados de formas distintas, e sua aplicação pode ser encarada como meio de repressão ao livre desenvolvimento de uma sociedade que vivencia o relativismo cultural.

Contudo, no campo do universalismo, a concepção maniqueísta do direito tende a ser um óbice à efetivação dos direitos humanos das pessoas com deficiência, em especial quando envolvem premissas de saúde, por servir como justificativa para práticas que violam os direitos humanos destes sujeitos, partindo do princípio que a dignidade humana é um elemento invariável - para àquela concepção (BOBBIO, 1992).

Em linhas gerais a denúncia do relativismo implica na quebra do paradigma (da igualade formal), valendo-se da crítica isonômica para fins de não apenas reconhecer direitos formais, mas, especialmente, concretiza-los na prática.

Com isso, pretende a versão relativista romper com a visão incapacitante da sociedade sobre a dignidade humana e os direitos fundamentais da pessoa com deficiência intelectual, já que a mera igualdade formal conduz estes sujeitos a uma situação de desvantagem social intensa gerada pelo não acesso aos direitos humanos, à socialização e às oportunidades necessárias ao crescimento para a vida adulta e cidadã.

Como se sabe os Direitos humanos, que nasceram universais (notadamente com a modernidade), pretendem não apenas - contemporaneamente - espraiar o seu exercício à uma coletividade determinada, lançando-se, conforme leciona Symonides (2003), a necessidade de garantir a vida dos homens em toda sua plenitude, invariavelmente, observando as diferenças entre os sujeitos.

Apesar dos contornos universais que possuem os Direitos Humanos, o grupo vulnerável objeto deste trabalho não consegue desfrutar desses direitos, pois, conforme aduz Comparato (2010), a humanidade é composta por uma minoria poderosa e uma maioria indigente. Nesta maioria insere-se a maior das minorias populares, pessoas com deficiência. 
Segundo dados do $\mathrm{IBGE}^{5}$, o Brasil tem aproximadamente 45 milhões de pessoas com algum tipo de deficiência, ou seja, $24 \%$ da população.

A inclusão da pessoa com deficiência é uma obrigação do Estado, e o tema da igualdade de oportunidades e não discriminação das pessoas com deficiência intelectual está surgindo cada vez com mais ressonância nos debates políticos, diferentemente dos antigos discursos superficiais de outrora, que traziam o obsoleto paradigma do assistencialismo e do modelo que reduz as ações da política pública ao setor saúde em se tratando de pessoas com deficiência intelectual.

Desta feita, tomando como ponto de partida o caráter relativista dos direitos deste grupo vulnerável e os embargos legais e culturais que impedem as pessoas com deficiência intelectual de exercerem de forma plena sua cidadania; problematiza-se a partir da aparente tensão entre a compatibilização das diretrizes legais e constitucionais pátrias com os termos da Convenção da ONU sobre os Direitos das Pessoas com Deficiência, em busca da máxima efetividade das normas de direitos humanos destes sujeitos, para que se possa atingir um cenário ideal participativo, onde as pessoas com deficiência intelectual possam se tornar de fato agentes multiplicadores da governança democrática, através do exercício da cidadania.

\section{Universalismo, Relativismo e Deficiência intelectual na perspectiva dos Direitos Humanos.}

Como sabido, os Direitos Humanos são direitos fundamentais do ser humano, indispensáveis para que ele possa participar plenamente da vida em sociedade. Como afirma Bobbio (1992), a Declaração universal dos Direitos Humanos de 1948 pode ser considerada a maior prova existente de consenso entre os seres humanos.

A mencionada Declaração de 1948 inaugura a concepção contemporânea de direitos humanos, caracterizada pela universalidade e indivisibilidade desses direitos. Universalidade porque, no dizer de Piovesan (2012, p. 38), clama pela extensão universal dos direitos humanos, "[...] sob a crença de que a condição de pessoa é o requisito único para titularidade de direitos, considerando o ser humano um ser essencialmente moral, dotado de unicidade existencial e dignidade [...]".

\footnotetext{
${ }^{5}$ IBGE, censo demográfico de 2010.
} 
Indivisibilidade, pois, conjuga de forma indivisível os direitos civis, políticos, econômicos, sociais e culturais, conforme observam Sohn e Buergenthal (1973, p. 516):

\begin{abstract}
A Declaração Universal de Direitos Humanos se distingue das tradicionais Cartas de direitos humanos que constam de diversas normas fundamentais e constitucionais dos séculos XVIII e XIX e começo do século XX, na medida em que ela consagra não apenas direitos civis e políticos, mas também direitos econômicos, sociais e culturais, como o direito ao trabalho e à educação.
\end{abstract}

Neste contexto o Universalismo Cultural propõe o estabelecimento de uma ética universal calcada na proteção cooperativa dos direitos humanos, como consequência da globalização social e dos processos de internacionalização desses direitos. Para Rabenhorst (2002), o discurso instituidor dos direitos humanos, após a promulgação da Declaração da ONU de 1948, traz a ideia de universalização do Direito com o intuito de promover valores universais inquestionáveis. Todavia, o mesmo autor assevera que, do ponto de vista histórico, este processo de universalização sofre oscilações entre as diversas formas de utopia comunitária.

Assim, Norberto Bobbio (2004, p.25), em seu contributo crítico, assevera que:

Do ponto de vista teórico, sempre defendi - e continuo a defender, fortalecido por novos argumentos - que os direitos do homem, por mais fundamentais que sejam, são direitos históricos, ou seja, nascidos em certas circunstâncias, caracterizadas por lutas em defesa de novas liberdades contra velhos poderes, e nascidos de modo gradual, não todos de uma vez, e nem de uma vez por todas. (2004, p.25)

Para Bobbio não é cabível a análise dos fundamentos e da natureza dos direitos humanos, tendo em vista que o problema se centra em como proteger tais direitos, envolvendo problemática não somente filosófica, mas principalmente jurídica e política. Ou seja, deve-se buscar a efetividade dos direitos humanos para impedir que, apesar de positivados em declarações solenes, eles sejam continuamente violados, pois a ideia universal dos direitos humanos como mera igualdade formal dá guarida a uma concepção segregadora.

Essa é justamente a proposta do relativismo, que, ao contrário do universalismo que prima em analisar o homem natural (descontextualizado), àquela concentra-se nos particularismos que caracterizam os homens, sobretudo nas diversidades existentes entre os sujeitos de direitos.

Do ponto de vista histórico o direito nem sempre cogitou proteger os "humanos" que na visão ocidentalizada não eram seres "perfeitos", ou seja, as pessoas com deficiência. A igualdade meramente formal trazida pelas solenes declarações de Direitos Humanos conduz estes sujeitos a uma situação de desvantagem social intensa, pois, na concepção relativista o 
ser humano é fruto do meio em que vive. Neste ínterim Boaventura (1997, p.17), aduz que “ [...] enquanto forem concebidos como direitos humanos universais, os direitos humanos tenderão a operar como localismo globalizado - uma forma de globalização de-cima-parabaixo [...]". Quando na verdade tais garantias deveriam ser perseguidas "de baixo para cima", ou seja, como consequência, como ponto de chegada.

A inclusão social através da defesa e proteção dos Direitos Humanos, proclamados na Declaração de 1948 e nos Pactos Internacionais sobre a matéria, está intimamente articulada com os diferentes contextos políticos, socioeconômicos e culturais em que se situa. Para Bobbio (2004, p. 69), a proteção das pessoas com deficiência, orientada pelo paradigma dos direitos humanos, se traduz no fato de que "[...] o próprio homem não é mais considerado como ente genérico, ou homem em abstrato, mas é visto na especificidade ou na concreticidade de suas diversas maneiras de ser em sociedade [...]".

Em que pese a necessidade de superar obstáculos e barreiras culturais, físicas ou sociais, na perspectiva da inclusão social da pessoa com deficiência intelectual, ainda é possível observar no Brasil a crença infundada de que pessoas com deficiência são frágeis e incapazes de se posicionar e enfrentar os desafios da vida. Esses sujeitos de direitos são vistos e tratados como pessoas vulneráveis, incapazes de tomar decisões, de expressar seus próprios desejos ou participar completamente da família e de outros contextos sociais, colocando-os em um crescente risco de vitimização, reforçando, segundo Soares (2010, p. 22), sua "identidade de invisibilidade [...] ou de visibilidade de sua incapacidade".

Enquanto a Convenção sobre os Direitos das Pessoas com Deficiência da ONU sustenta de forma universalista o exercício pleno da cidadania pelas pessoas com deficiência, a visão incapacitante da pessoa com deficiência, reflexo de uma qualidade multicultural da sociedade brasileira, baseada em uma visão paternalista e biomédica da deficiência, tem como consequência a desigualdade ao acesso à cidadania deste grupo vulnerável, através dos processos desiguais de acesso à cidadania adotadas pelo legislador pátrio. Assim, para Rabenhorst (2002), as posições universalistas, as quais impõe um alinhamento dos valores consagrados pelo Ocidente, apresentam-se como um aparelho aparentemente utópico.

Neste contexto, cumpre mencionar que o conceito de Deficiência intelectual passou no decorrer dos anos por diversas definições e terminologias para caracteriza-lo. Hoje a Deficiência Intelectual, segundo a Associação Americana sobre Deficiência Intelectual do Desenvolvimento, caracteriza-se por um funcionamento intelectual inferior à média, 
associado a limitações adaptativas em pelo menos duas áreas de habilidades (comunicação, autocuidado, vida no lar, adaptação social, saúde e segurança, uso de recursos da comunidade, determinação, funções acadêmicas, lazer e trabalho), que ocorrem antes dos 18 anos de idade.

A Convenção sobre os Direitos das Pessoas com Deficiência da ONU de 2006, define em seu artigo $1^{\circ}$ a conceituação de pessoa com deficiência como sendo "aquelas que têm impedimentos de longo prazo de natureza física, mental, intelectual ou sensorial, os quais, em interação com diversas barreiras, podem obstruir sua participação plena e efetiva na sociedade em igualdades de condições com as demais pessoas".

No panorama da deficiência intelectual é imprescindível encontrar definições apropriadas para cidadania, o que pode ser feito através de Adela Cortina (2005, p.45), para quem cidadania "é conjunto de direitos e liberdades políticas sociais e econômicas, já estabelecidas ou não pela legislação". Tratando de cidadania Hannah Arendt (1983) a considera como sendo a prerrogativa política do direito a ter direitos, criticando a concepção exclusivamente jurídica de cidadania como mera intitulação de direitos, indicando a necessidade de participação dos cidadãos na esfera pública.

Tomando por base estas ideias sobre cidadania, necessário pensar agora sobre a mesma no âmbito da pessoa com deficiência intelectual. Ressalte-se que o direito de exercer uma cidadania plena, como o direito à educação, à participação na vida pública e política, o acesso à justiça, e os concernentes as relações familiares como o casamento, a constituir família, à maternidade e paternidade e à vida sexual, se constitui em direito fundamental inerente à própria condição de ser humano, decorrente do princípio da dignidade da pessoa humana, o qual é definido por Sarlet (2012, p. 6), como sendo:

\begin{abstract}
A qualidade intrínseca e distintiva de cada ser humano que o faz merecedor do mesmo respeito e consideração por parte do Estado e da comunidade, implicando, neste sentido, um complexo de direitos e deveres fundamentais que assegurem a pessoa tanto contra todo e qualquer ato de cunho degradante e desumano, como venham a lhe garantir as condições existenciais mínimas para uma vida saudável, além de propiciar e promover sua participação ativa e corresponsável nos destinos da própria existência e da vida em comunhão com os demais seres humanos.
\end{abstract}

Desta premissa, observa-se a dignidade como princípio constitucional fundamental, um verdadeiro atributo da personalidade humana. Assim, Diniz (2007), trata da deficiência intelectual como condição da pessoa humana com impedimentos, limitações de atividades ou restrições de participação, mas que não retira do indivíduo os seus atributos de pessoa humana e nem o incapacita de exercer plenamente sua cidadania. 
Neste sentido, pode-se afirmar que todo ser humano, adulto ou criança com impedimentos de ordem intelectual são cidadãos. Desta feita Nussbaum (2013, p.120), afirma que "[...] qualquer sociedade decente deve responder às suas necessidades de assistência, educação, auto respeito, atividade e amizade".

Seguindo este entendimento Comparato (2010, p. 1), diz que “[...] a revelação de que todos os seres humanos, apesar de inúmeras diferenças biológicas e culturais que os distinguem entre si, merecem igual respeito [...] - nenhum indivíduo, gênero, etnia, classe social, grupo religioso ou nação - pode firmar-se superior aos demais".

Todavia, para Nussbaum (2013, p.121) as teorias de contrato social caracterizam os cidadãos como membros plenamente cooperantes e dotados de racionalidade particularmente idealizada, aduzindo que:

Está claro que essas teorias só abordarão os impedimentos mentais graves, e suas deficiências associadas, em um momento posterior, depois que as instituições básicas da sociedade já tenham sido formuladas. Na prática isso significa que pessoas com impedimentos mentais não estão entre aquelas para as quais e em reciprocidade com as quais as instituições básicas da sociedade são estruturadas.

Com efeito, a negação ao exercício da cidadania afronta diretamente a natureza humana. A pessoa com deficiência intelectual não pode ser considerada "menos humana" ou possuidora de uma humanidade condicionada ou restrita.

\section{A Convenção sobre os Direitos das Pessoas com Deficiência e a efetividade do exercício da cidadania no Brasil.}

A partir da necessidade de garantir que todas as pessoas com deficiência possam exercer plenamente e sem discriminação os direitos humanos e liberdades fundamentais, a Convenção sobre os Direitos das Pessoas com Deficiência (2006) se constitui como um marco na história do Brasil, sendo o documento mais importante em relação a pessoa com deficiência.

Dentre os direitos que a Convenção garante, destacamos a afirmação do direito ao acesso à justiça, ao casamento, à educação e a participação na vida política e pública. Logo no $\operatorname{artigo~} 1^{\circ}$, a convenção apresenta o propósito de "promover, proteger e assegurar o exercício pleno e equitativo de todos os direitos humanos e liberdades fundamentais por todas as pessoas com deficiência”, estabelecendo ainda que os Estados signatários deverão tomar 
medidas efetivas e apropriadas a fim de eliminar a discriminação contra pessoas com deficiência para a realização dos direitos reconhecidos. Tratando do direito à justiça o artigo 13 garante:

1. Os Estados Partes assegurarão o efetivo acesso das pessoas com deficiência à justiça, em igualdade de condições com as demais pessoas, inclusive mediante a provisão de adaptações processuais adequadas à idade, a fim de facilitar o efetivo papel das pessoas com deficiência como participantes diretos ou indiretos, inclusive como testemunhas, em todos os procedimentos jurídicos, tais como investigações e outras etapas preliminares. 2. A fim de assegurar às pessoas com deficiência o efetivo acesso à justiça, os Estados Partes promoverão a capacitação apropriada daqueles que trabalham na área de administração da justiça, inclusive a polícia e os funcionários do sistema penitenciário.

É sabido que a democracia tem uma de suas vertentes na concreta e efetiva participação do cidadão, garantindo o acesso à justiça de forma indiscriminada. Embora o texto da convenção garanta o efetivo acesso das pessoas com deficiência à justiça em igualdade de condições com as demais, ao analisarmos nosso ordenamento jurídico processual civil constatamos que esta garantia é mais retórica que concreta, na medida em que não se tem normas nem práticas que viabilizam sua realização.

O mesmo acontece com o direito à educação. A constituição Federal e a Convenção sobre os Direitos das Pessoas com Deficiência (2006) são claras em relação ao direito à educação inclusiva das pessoas com deficiência intelectual. A supramencionada convenção assevera em seu artigo 24 que " os Estados Partes reconhecem o direito das pessoas com deficiência à educação. Para efetivar esse direito sem discriminação e com base na igualdade de oportunidades, os Estados Partes assegurarão sistema educacional inclusivo em todos os níveis, bem como o aprendizado ao longo de toda a vida [...]"

Contudo, o que se tem hoje no Brasil, tanto na rede pública quanto na rede particular de ensino, é o argumento de que as escolas não estão preparadas para receber alunos com deficiência intelectual. A este respeito Nussbaum (2013, p.121), aduz que "uma abordagem satisfatória da justiça humana requer reconhecer a igualdade na cidadania para pessoas com impedimentos, inclusive impedimentos mentais, e apoiar apropriadamente o trabalho de sua assistência e educação [...]".

No que concerne às relações familiares a convenção estabelece em seu art. 23 que os Estados signatários deverão tomar medidas efetivas e apropriadas a fim de eliminar a discriminação contra pessoas com deficiência, em todos os aspectos relativos a casamento, família, paternidade e relacionamentos, em igualdade e condições com as demais pessoas, de 
modo a assegurar que seja reconhecido o direito das pessoas com deficiência de casar e estabelecer família.

As pessoas com deficiência intelectual, sejam adolescentes ou adultas, sonham muitas vezes encontrar alguém para compartilhar o amor, casar, ter filhos. Contudo, quando mulheres e homens desse grupo social assumem relações amorosas com intuito de constituir família, geralmente as pessoas reagem com surpresa ou medo, uma vez que principalmente mulheres com deficiência são vistas como pessoas fragilizadas, incapazes e anormais. Como afirmam Kempton e Kahn (1991), enfrentam resistência do próprio Estado, através de restrições legais ao casamento, em grande parte devido ao temor da procriação. Ocorre que, com a ressalva proposta por Koller et al (1988), ainda que sem a devida proteção legal, pessoas com deficiência contraíram matrimônio, procriaram, criaram filhos e foram capazes de gerir suas vidas.

Quanto a participação das pessoas com deficiência na vida pública e política, embora o artigo 14 da Constituição Federal garanta os direitos políticos a todos os cidadãos brasileiros, com valor igual para todos, o artigo 29 da já mencionada Convenção vem reforçar os direitos políticos das pessoas com deficiência, pois é certo que a nossa sociedade esquece ou relativiza a participação das pessoas com deficiência nos processos políticos. $\mathrm{O}$ mencionado artigo da Convenção afirma que:

Os Estados Partes garantirão às pessoas com deficiência direitos políticos e
oportunidade de exercê-los em condições de igualdade com as demais pessoas, e
deverão: a) Assegurar que as pessoas com deficiência possam participar efetiva e
plenamente na vida política e pública, em igualdade de oportunidades com as
demais pessoas, diretamente ou por meio de representantes livremente escolhidos,
incluindo o direito e a oportunidade de votarem e serem votadas, mediante, entre
outros [...].

Deste dispositivo depreende-se o direito da pessoa com deficiência de exercer seu direito político de votar e ser votado, bem como na participação de referendos e plebiscitos, ou mesmo participando da elaboração de leis. Ainda no que concerne à participação na vida pública podemos destacar a participação destes cidadãos em ONGs, a fim de que possam se envolver em questões públicas relacionadas aos interesses da própria pessoa com deficiência intelectual, ou mesmo de questões outras de interesse da sociedade.

Todavia, informações contidas no Relatório brasileiro sobre o cumprimento das disposições da Convenção (2008-2010), traduzem a falta de comprometimento do Estado brasileiro em implementar medidas efetivas capazes de eliminar a discriminação contra 
pessoas com deficiência, a fim de assegurar todos estes direitos fundamentais aqui elencados, de modo que as pessoas com deficiência intelectual possam exercer de forma plena sua cidadania. O Brasil não conseguiu adotar disposições de direito interno para adequar a produção normativa doméstica à Convenção da ONU, acabando por mitigar a sua efetividade e aplicabilidade imediata.

A incorporação da Convenção ao Direito brasileiro com status de emenda constitucional, confere eficácia à norma, mas não a sua plena efetividade. A afirmação dos direitos da pessoa com deficiência no âmbito internacional e sua incorporação no ordenamento jurídico interno não é, por si só, capaz de realizá-los, pois, conforme afirma Abreu (2008), os direitos só existem dentro de um ambiente que possibilite sua efetivação.

Não é à toa que a própria Convenção determina adoção de medidas concretas e bem definidas através de prestações positivas por parte do Estado, a fim de assegurar os direitos nela dispostos. O Estado tem o dever de salvaguardar a autonomia da pessoa com deficiência, com todas as limitações e mudanças que a sua condição implica, a fim de que o indivíduo possa exercer sua cidadania.

Contudo, o descaso e desrespeito por parte do Brasil com o aparato normativo consagrado na Convenção, retira da pessoa com deficiência a liberdade de vivenciar seus desejos e de serem protagonistas de suas escolhas. Diante disto, conforme leciona Sorto (2011), não pode haver exercício da cidadania sem liberdade.

Neste contexto, verificamos que a própria legislação civilista se apresenta como entrave na harmonização entre a normativa doméstica e a Convenção da ONU ao tratar pessoa com deficiência intelectual como enfermo mental, isto por influência do modelo biomédico da deficiência. Nos dizeres de Barnes et al (2002), cumpre mencionar que deficiência não se resume a uma lista de enfermidades e lesões da perícia biomédica do corpo humano, abrangendo a relação de desigualdade imposta por ambientes com barreiras ao corpo com impedimentos.

Estas premissas são reforçadas por Nussbaum (2013, p.191), ao afirmar que "[...] a falha em assegurar esses direitos aos cidadãos constitui uma violação particularmente grave da justiça básica, pois se considera que estejam implícitos nas próprias noções de dignidade humana e de uma vida segundo a dignidade humana".

A Convenção sobre os Direitos das Pessoas com Deficiência contribui de forma decisiva para a promoção dos direitos humanos no Brasil, contudo, o sucesso da efetividade 
desse instrumento internacional no âmbito dos direitos já elencados, requer ampla sensibilização do Estado brasileiro na adoção de medidas efetivas e apropriadas para adequar a legislação Civil brasileira à Convenção, o que pode viabilizar avanços concretos na defesa do exercício dos direitos da cidadania. Neste contexto, Piovesan (2012, p. 48), assevera que:

O propósito maior da Convenção é promover, proteger e assegurar o pleno exercício
dos direitos humanos das pessoas com deficiência, demandando dos Estados - Partes
medidas legislativas, administrativas e de outra natureza para a implementação dos
direitos nela previstos. Introduz a Convenção o conceito de "reasonable
accommodation", apontando o dever do Estado de adotar ajustes, adaptações, ou
modificações razoáveis e apropriadas para assegurar às pessoas com deficiência o
exercício dos direitos humanos em igualdade de condições com as demais. Violar o
"reasonable accommodation" é uma forma de discriminação nas esferas pública e
privada.

Assim, a partir das garantias da pessoa com deficiência concernentes ao acesso à justiça, ao casamento, à educação e a participação na vida política e pública, bem como os embargos legais que as impedem de exercer de forma plena sua cidadania, é que o Estado deve adotar medidas legislativas a fim de superar os entraves para a harmonização entre a Convenção sobre os Direitos das Pessoas com Deficiência e o Ordenamento Jurídico brasileiro.

\section{Reflexões sobre a eficácia social das normas relativas à proteção da pessoa com deficiência}

Uma das preocupações dispostas no preâmbulo da Convenção sobre os Direitos das Pessoas com Deficiência da ONU de 2006, elevada ao status de Emenda Constitucional na ordem jurídica brasileira, consiste justamente no fato de que, apesar dos diversos instrumentos e compromissos assumidos pelos atores que estão vinculados à proteção da pessoa com deficiência, esta categoria social continua a enfrentar barreiras contra sua participação como membros iguais na sociedade.

Se por um lado houve avanços, conquistas legislativas e jurisprudenciais, por outro se verifica que a eficácia social, ou seja, a efetividade normativa de alguns direitos resta prejudicada, principalmente quando se trata do direito ao casamento, bem como ao de constituir família. Para exemplificar, mesmo diante da Convenção de 2006, o Estado brasileiro não tem conseguido garantir a compatibilização entre a produção normativa 
doméstica e a referida Convenção, acabando por mitigar a efetividade e aplicabilidade normativa que se deveria garantir aos direitos em comento.

Nesse sentido há uma toda sociologia dos direitos humanos a denunciar a industrialização (ou massificação) da forma - ou o protagonismo legislativo em detrimento daquilo que se deveria ter como obvio: a concreção de tais aspirações humanas.

O direito, portanto, não tem nem pode ter funções; ainda não há espaço para a melancolia, mas sim, de encontrar novas razões para um compromisso que vai no sentido da aplicação dos direitos e não da mera proclamação [...]. Por que continuam a existir a fome, a escravidão, a doença, apesar de ser proclamado o direito de todo homem a ser libertado? O que não funciona? É um problema da clareza da lei, de eficiência do sistema judicial e dos burocratas, ou o que mais? (PANNARALE, 2014, p. 34)

A Convenção sobre os Direitos das Pessoas com Deficiência é o primeiro tratado internacional de direitos humanos aprovado na forma do $\S 3^{\circ}$ do art. $5^{\circ}$ da Constituição Federal e o estudo sobre a eficácia social de seus dispositivos merecem estudo minucioso. Com efeito, somente a positivação de um direito não basta para garantir ações efetivas, uma vez que "uma norma constitucional não se realiza (efetividade) se inexistir a mínima chance de ser aplicada". (BULLOS, 2014, p. 478). Neste sentido, o mesmo autor obtempera que eficácia social pode ser entendida como:

(...) a incidência concreta e regular das normas constitucionais sobre os acontecimentos da vida (...). Norma constitucional efetiva, portanto, é aquela obedecida, seguida e aplicada, correspondendo aos fatores reais do poder que regem a sociedade. Sem eficácia social a vontade da constituição não se realiza, porque seus comandos perdem a importância. (BULLOS, 2014, p. 477)

O problema da eficácia social é desafiador em face da inexistência (ou alegação dela) de que o poder público não possui meios para fazer valer os direitos de pessoas inseriras em grupos sociais vulneráveis, ou mesmo em virtude do simbolismo de algumas normas e diplomas que carecem de efetividade, servindo tão somente ao interesse do discurso político.

Assim, por vezes, diante de questões econômicas ou ausência de políticas públicas, o Direito é preterido ou impossibilitado. Desta feita, Mendes (2015, p.642), ensina que "nesse contexto, passa a ter significativo relevo o tema da "reserva do possível', especialmente ao evidenciar a 'escassez dos recursos' e a necessidade de se fazerem escolhas alocativas", por conseguinte, cabe investigar as razões pelas quais certos direitos da pessoa com deficiência não são garantidos.

Certo é que não é de hoje a tensão havida no contexto do Direito enquanto forma e substância, vale dizer, questões éticas que invadem tal discussão foram desde os gregos já 
denunciadas. No limiar desse "neoconstitucionalismo" brasileiro (não se olvide a problemática do constitucionalismo andino que padece do mesmo mal de ineficácia) forçoso é reconhecer que a eleição de um valor de conteúdo jurídico indeterminado (a dignidade humana), fundamento que é do Estado democrático de direito não trouxe mais divisas do que críticas.

Em relação ao aspecto simbólico da norma, importa destacar as lições de Marcelo Neves, jusfilósofo brasileiro que enfrentou o estudo sobre legislação simbólica ${ }^{6}$. Segundo o autor, a legislação simbólica "aponta para o predomínio, ou mesmo hipertrofia, no que se refere ao sistema jurídico, da função simbólica da atividade legiferante e do seu produto, a lei, sobretudo em detrimento da função jurídico-instrumental" (NEVES, 2011, p.23).

$\mathrm{O}$ autor aduz que a atividade legislativa constitui um momento de confluência concentrada entre sistemas políticos e jurídicos, definindo legislação simbólica como:

\begin{abstract}
[...] produção de texto cuja referência manifesta à realidade é normativo-jurídica, mas que serve, primária e hipertroficamente, a finalidades políticas de caráter não especificamente normativo-jurídico (...) o conceito de legislação simbólica deve referir-se abrangentemente ao significado específico do ato de produção e do texto produzido, revelando que o sentido político de ambos prevalece hipertroficamente sobre o aparente sentido jurídico-normativo. (NEVES, 2011, p. 30-31)
\end{abstract}

Na legislação simbólica para confirmação de valores sociais, a atuação dos agentes políticos visa estabelecer um posicionamento em relação a determinado conflito social, ou seja, a atividade legiferante tem escopo de afirmar o posicionamento do Legislador em favor de um grupo social em detrimento de outro, aduzindo um grau de inferioridade do grupo considerado perdedor.

Neste sentido, conforme pontifica Lenza (2013, p.79), a eficácia normativa da lei fica em segundo plano, pois, "o grupo prestigiado procura influenciar a atividade legiferante, fazendo prevalecer os seus valores contra os do grupo adversário", produzindo a sensação de status ou respeito às ideias do grupo vencedor.

Assim, diante de valores antagônicos, a confirmação de um deles informa tão somente um efeito simbólico, a ratificação de valores sociais de forma a distinguir grupos, constituindo, políticas simbólicas que "apontam para a glorificação ou degradação de um grupo em oposição a outros dentro da sociedade" (LENZA, 2013, p.80). Como exemplo significativo, Neves (2011, p. 34-35), cita a legislação sobre imigração de estrangeiros:

\footnotetext{
${ }^{6}$ Tendo por base a análise de diversos autores, Marcelo Neves busca definir preliminarmente o conceito de símbolo em Freud, Jung, Lacan, Cassirer, Lévi -Strauss, Bourdieu, Castoriadis, Firth, Luhmann, dentre outros, e a partir disto apresenta a ideia de legislação simbólica.
} 
O debate sobre uma legislação mais rigorosa ou mais flexível em relação aso estrangeiros seria predominantemente simbólico: nesse caso, a legislação teria uma função simbólica muito importante, na medida em que influenciaria a visão que os nacionais têm dos imigrantes - com o estranhos e invasores, ou como vizinhos, colegas de trabalho, de estudo, de associação e, portanto, "parte da sociedade". Primariamente, a legislação funcionaria como uma "etiqueta" em relação à figura do imigrante estrangeiro.

Outro caráter da legislação simbólica (demonstração da capacidade de ação do Estado), também denominada de "legislação-álibi”, informa uma atividade legiferante que visa assegurar confiança no sistema jurídico e político em face de fatos sociais que causam insatisfação coletiva.

Assim, uma legislação-álibi aduz uma solução fictícia para problemas sociais relevantes que eclodem na sociedade, trazendo uma sensação de atuação efetiva dos agentes políticos. Neves (2011, p. 39), clarifica que a espécie tem intuito de criar a imagem de um Estado "que responde normativamente aos problemas reais da sociedade, embora as respectivas relações sociais não sejam realmente normatizadas de maneira consequente conforme o respectivo texto legal". O autor complementa o raciocínio afirmando que a legislação-álibi “constitui uma forma de manipulação ou de ilusão que imuniza o sistema político contra alternativas, desempenhando uma função ideológica” (NEVES, 2011, p. 39).

A legislação-álibi pode ser verificada em leis criadas em face de comoção social, normalmente com atuação intensa da imprensa, servindo por vezes à prestação de contas dos políticos nos períodos eleitorais, todavia, remete a um texto sem efetividade, sem condições de assegurar o que o Legislador propõe. É evidente que o uso desmedido da espécie tende a gerar um efeito contrário, uma vez que o abuso de tal recurso político pode gerar um descrédito do sistema jurídico.

Outro aspecto da legislação simbólica é adiar a solução de conflitos sociais através de compromissos dilatórios. É o produto de atividade legiferante para transferir a solução de um determinado conflito social para um futuro incerto, por meio da criação de uma lei que satisfaz os interesses partidários.

Mais uma vez, a função jurídico-instrumental é colocada em segundo plano, uma vez que as divergências entre os interesses de grupos políticos é a finalidade precípua.

Reduzir o Estado Constitucional assentado que é na dignidade da pessoa humana ao que sinalizara Forsthoff (1986), ou seja, a um modelo meramente formal, no qual a codificação se bastaria em si mesma - desde que contemplasse os elementos estruturais de 
uma Constituição não é mais suficiente para responder aos reclamos das chamadas minorias, ai incluídas as pessoas com deficiência.

Outro entrave não menos complexo é o da plataforma dos direitos fundamentais. A se utilizar a crítica ricoeuriana tem-se que a democracia enquanto terreno para o estabelecimento e efetivação dos direitos humanos fundamentais ${ }^{7}$ também padece de um processo crônico de esgotamento de seu matiz representativo, hipótese que desafiaria a força normativa da Constituição exatamente pelo fato de conduzir a certa hipertrofia das contradições próprias de um Estado que se quer social, mas baseado em governabilidade frágil do ponto de vista da legitimidade popular (RICOEUR, 2011).

Do exposto, no que diz respeito ao direito da pessoa com deficiência de exercer sua cidadania, deve-se ter a devida atenção se existe concretização normativa, sob pena de se ter tão somente legislações simbólicas do tipo legislação-álibi ou legislação para adiar o adimplemento de direitos para um futuro incerto pelo Estado. Por outro lado, os entraves à realização de direitos podem envolver outras instituições em face de valores morais e religiosos. Com efeito, Marineia Crosara de Resende e Roosevelt Leão Júnior (2008, p. 82), esclarecem:

\begin{abstract}
Para algumas pessoas com deficiência tem sido negado o direito à escolha de se constituir família: nos moldes tradicionais, como num caso que aconteceu numa cidade no interior de Minas Gerais, na década de 1990, onde o representante de uma Igreja negou-se a realizar o casamento, alegando que tal casal não poderia gerar filhos; ou mesmo através da educação em família, onde alguns pais proíbem seus filhos com deficiência de namorarem ou mesmo de conviverem com outras pessoas, inclusive, proibindo-os de saírem de casa, ou pior ainda, desacreditam na possibilidade de seus filhos poderem oferecer amor e se fazerem ser amados, destruindo assim, qualquer possibilidade de auto aceitação da própria condição, de ter uma deficiência.
\end{abstract}

Depreende-se que a eficácia social dos direitos ora expostos é trabalho desafiador, pois, depende de execução de políticas públicas, bem como da própria mudança cultural no sentido de enxergar a pessoa com deficiência como um ser que necessita de proteção e garantia de direitos, mas que é capaz de ter uma vida plena.

\footnotetext{
7 As teorias mais sofisticadas apontam para a tecnicidade do termo em razão da característica de complementaridade que marca tanto os direitos humanos, como os fundamentais.
} 


\section{Conclusões}

De acordo com as estatísticas do Censo IBGE/2010, o Brasil tem aproximadamente 45 milhões de pessoas com algum tipo de deficiência, ou seja, 24\% da população. Neste percentual encontra-se considerável número de pessoas com deficiência intelectual. Diante deste quadro populacional, não se pode olvidar que estes cidadãos, em um contexto jurídico social de discriminação, necessitam da guarida do Estado a fim de que possam exercer os direitos civis afirmados na Convenção sobre os Direitos das Pessoas com Deficiência.

A história é prova de que o grupo social das pessoas com deficiência tem sofrido constantes processos de exclusão e desempoderamento, impossibilitando-as de desfrutar de direitos humanos básicos, como o direito à educação, à participação na vida pública e política, o acesso à justiça, e aquelas concernentes as relações familiares como o casamento, a constituir família, à maternidade e paternidade e à vida sexual. A visão simplista e reducionista sobre a pessoa com deficiência traz como consequência a ideia do estereótipo de "eterna criança" que precisa de cuidados, mesmo na fase adulta, gerando dependência familiar e controle de escolhas pessoais, restringindo indiscriminadamente sua história de vida à voz da autorização de responsáveis legais.

A Convenção sobre os Direitos das Pessoas com Deficiência, homologada pela Assembléia das Nações Unidas em 13 de dezembro de 2006 e incorporada à legislação brasileira em 2008, se apresenta como a mais nova e inclusiva norma internacional para a afirmação dos direitos fundamentais das pessoas com deficiência.

Contudo esta Convenção sustenta de forma universalista o exercício pleno da cidadania pelas pessoas com deficiência, o que não se traduz em efetividade, já que na análise preliminar do relatório brasileiro relativo ao cumprimento das disposições da Convenção (2008-2010), se observa que o Estado brasileiro não adotou soluções efetivas de inclusão para assegurar o direito das pessoas com deficiência de exercerem de forma plena sua cidadania, através do gozo dos direitos já mencionados. Subsiste, assim, um abismo entre a legislação nacional e as garantias consagradas na Convenção, criando um ambiente que impede a plena e efetiva participação dessas pessoas na sociedade, em igualdade de oportunidades em todos os aspectos relativos a cidadania.

Após análise do reconhecimento internacional dos direitos humanos da pessoa com deficiência através dos dispositivos da Convenção que dispõem sobre aspectos relativos ao 
exercício da cidadania através de direitos historicamente conspurcados, e os processos de exclusão e desempoderamento que sofre esse grupo social em virtude da necessidade de realização das normas de direitos humanos quanto à pessoa com deficiência intelectual em todos os aspectos relativos ao exercício da cidadania, em igualdade de condições com as demais pessoas, depreende-se o dever do Estado em adotar disposições de direito interno para compatibilização do ordenamento jurídico à Convenção, a fim de assegurar o exercício dos direitos e liberdades constantes neste diploma de Direitos Humanos.

A compatibilização do ordenamento jurídico brasileiro à Convenção sobre os Direitos das Pessoas com Deficiência, a partir da quebra e transição do paradigma do modelo biomédico da deficiência adotado pelo legislador pátrio para o modelo social integrador da deficiência consagrado no preâmbulo da Convenção, pode diminuir a discriminação e assegurar o direito de as pessoas com deficiência de exercerem efetivamente sua cidadania.

Conforme leciona Boaventura (1997), é preciso superar a visão meramente universalista dos Direitos Humanos para que haja uma transformação na concepção e da prática destes direitos, para que eles passem a ser vistos através de uma visão relativista no contexto do asseguramento normativo das pessoas com deficiência, como forma de afastar a universalidade dos direitos humanos de uma visão abstrata e meramente formal.

Com isso, pretende a versão relativista romper com a visão incapacitante da sociedade sobre a dignidade humana e os direitos fundamentais da pessoa com deficiência intelectual, já que a mera igualdade formal conduz estes sujeitos a uma situação de desvantagem social intensa gerada pelo não acesso aos direitos humanos, à socialização e às oportunidades necessárias ao crescimento para a vida adulta e cidadã.

\section{REFERÊNCIAS}

ABENDROTH, Wolfgang, FORSTHOFF, Ernst \& DOEHRING, Karl. El Estado Social. Madrid, Centro de Estudios Constitucionales, 1986.

ABREU, Haroldo. Para além dos direitos: cidadania e hegemonia no mundo moderno. Rio de Janeiro: Editora UFRJ, 2008.

ARENDT, Hannah. A condição humana; as esferas públicas e privadas; Ação; A vita activa e a era moderna. In: A condição humana. Rio de Janeiro: Forense Universitária. 1983. p. $15-88 ; 188-338$. 
BARNES, Colin; BARTON, Len; OLIVER, Mike. Disability studies today. Cambridge: Polity Press, 2002.

BOBBIO, Norberto. A era dos direitos. Trad. Carlos Nelson Coutinho. Rio de Janeiro: Elsevier, 2004.

BRASIL. Constituição da República Federativa do Brasil de 1988. Ed. revisada e atualizada até a Emenda Constitucional no 84, de 02/12/14. Brasília: Senado Federal, 2014.

Decreto Legislativo $\mathrm{n}^{\circ} 186$ de 2008. Aprova o texto da Convenção sobre os Direitos das Pessoas com Deficiência e de seu Protocolo Facultativo, assinados em Nova Iorque, em 30 de março de 2007. Diário Oficial da União, Brasília, 10 de Julho de 2008.

Decreto $n^{\circ}$ 6.949, de 25 de Agosto de 2009. Promulga a Convenção Internacional sobre os Direitos das Pessoas com Deficiência e seu Protocolo Facultativo, assinados em Nova York, em 30 de março de 2007. Diário Oficial da União, Brasília, 26 de Agosto de 2009.

BULOS, Uadi Lammêgo. Curso de direito constitucional. $8^{\text {a }}$ ed. rev. e atual. de acordo com a Emenda Constitucional n. 76/2013. São Paulo: Saraiva, 2014.

COMPARATO, Fábio K. A afirmação histórica dos direitos humanos. São Paulo: Saraiva, 2010.

CORTINA, Adela. Las fronteras de la persona: el valor de los animales, la dignidade de los humanos. Madrid: Taurus, 2009.

DINIZ, Débora. O que é deficiência. São Paulo: Editora Brasiliense, 2007.

BARBOSA, Lívia; SANTOS, Wederson Rufino dos. Deficiência, Direitos Humanos e Justiça. SUR - Revista Internacional de Direitos Humanos, Volume 6, 2009, p. 65-77.

PEREIRA, Natália; SANTOS, Wederson. Deficiência e perícia médica: os contornos do corpo. Reciis, Volume. 3, n. 2, 2009, p. 16-23.

FARIAS, Adenize Queiroz de. Gênero e Deficiência: Vulnerabilidade Feminina, Ruptura e Superação. 230 f. Dissertação de Mestrado, Programa de Pós-graduação em Educação, Universidade Federal da Paraíba (UFPB), 2011.

KEMPTON, W.; KAHN, E. Sexuality and people with intellectual disabilities: A historical perspective. Sexuality and Disability, volume 9, 1991, p. 93-111.

KOLLER, H.; RICHARDSON, S. A.; KATZ, M. Marriage in a young adult mentally retarded population. Journal of Mental Deficiency Research, 1998, p.93-102.

LENZA, Pedro. Direito constitucional esquematizado. 16ª ed. São Paulo: Saraiva, 2012. 
MENDES, Gilmar Ferreira. Curso de Direito Constitucional. $29^{a}$ ed. São Paulo: Saraiva, 2015 .

NEVES, Marcelo. A Constitucionalização Simbólica. $3^{a}$ ed. São Paulo: Martins Fontes, 2011.

NUSSBAUM, Martha C. Los contratos sociales y três problemas no resueltos de La justicia (cap. 1); Las discapacidades y el contrato social (cap. 2); Capacidades y discapacidades (cap. 3). In: Las fronteras de la justicia: consideraciones sobre la exclusión. Trad. Ramon Vilà Vernis; Albino Santos Mosquera. Barcelona: Paidós, 2012. P. 21-225.

ORGANIZAÇÃO DAS NAÇÕES UNIDAS - ONU. 2006a. Convenção sobre os Direitos das Pessoas com Deficiência. Doc. A/61/611, Nova Iorque, 13 dez.

2006b. Protocolo Facultativo à Convenção sobre os Direitos das Pessoas com

Deficiência. Doc. A/61/611, Nova Iorque, 13 dez.

PANNARALE, Luigi. A Justiça dos Direitos Humanos - por um catalogo de Direitos Humanos. In: SILVA, Luciano Nascimento; DEL BENE, Caterina. Justiça e Direitos Humanos: estudos do Centro di Studi Sul Rischio dell’Università Del Salento. Curitiba: Juruá, 2014.

PIOVESAN, Flávia. Convenção da ONU sobre os direitos das pessoas com deficiência: inovações, alcance e impacto. In: FERRAZ, Carolina Valença et al. Manual dos direitos da pessoa com deficiência. São Paulo: Saraiva, 2012.

RABENHORST, Eduardo. Direitos humanos e globalização contra-hegemônica: notas para o debate. In: Lyra, Rubens Pinto (org.). Direitos humanos: os desafios do século XXI uma abordagem interdisciplinar. Brasília: Brasília Jurídica, 2002, p. 17-24.

RESENDE, Marineia Crosara de; LEÃO JÚNIOR, Roosevelt. Artigo 23 - Respeito pelo lar e pela família. In: BRASIL. A Convenção sobre Direitos das Pessoas com Deficiência Comentada /Coordenação de Ana Paula Crosara Resende e Flavia Maria de Paiva Vital _ Brasília : Secretaria Especial dos Direitos.

RICOEUR, Paul. Hermenêutica e ideologias. 2.ed. Petrópolis: Vozes, 2011.

SANTOS, Boaventura de Sousa. Para uma concepção multicultural dos Direitos Humanos. Revista crítica de ciências sociais, $\mathrm{n}^{\circ}$ 48, 1997, p. 11-22.

SARLET, Ingo. A eficácia do direito fundamental à segurança jurídica: dignidade da pessoa humana, direitos fundamentais e proibição de retrocesso social no direito constitucional brasileiro. Disponível em: http://www.egov.ufsc.br/portal/sites/default/files/anexos/15197-15198-1-PB.pdf. Acesso em: 14 agosto de 2016.

SIMONIDES, Janusz. Direitos humanos: novas dimensões e desafios. Brasília: UNESCO / SEDH, 2003. 
SOARES, Alessandra Miranda Mendes. Nada sobre nós sem nós: Estudo sobre a formação de jovens com deficiência para o exercício da autoadvocacia em uma ação de extensão universitária. Dissertação de Mestrado. Programa de Pós-graduação em Educação, Universidade Federal da Paraíba (UFPB): 2010.

SOHN, Louis B.; BUERGENTHAL, Thomas. International protection of human rights. Indianápolis: The Bobbs-Merrill Company, 1973.

SORTO, Fredys Orlando. O projeto jurídico de cidadania universal: reflexões à luz do direito de liberdade. Anuário Hispano-Luso-Americano de Derecho Internacional, Madrid, vol. 20, p. 103-126, ene./dic. 2011. 